\title{
Influence of Communication and Motivation to Team Innovation
}

\author{
Lei Qian
}

\author{
University of Melbourne \\ qianlq@student.unimelb.edu.au
}

\begin{abstract}
Teamwork become a trend of an effective method to deal with one project because it could gather people from different fields and consolidate their power to solve one problem. But some teams are not effective and cannot generate innovative solutions and great outcome, which waste resources on minimizing cost of improve innovation. Hence, it should find out what factors are key elements for team innovation. In this thesis, the author would focus on how communication and motivation impact on team innovation. This thesis combines and analyses some second hand questionary statistics data from different industries like hotel, tourist, medical and so on. According to these data, they show that communication have positive relationship to team innovation through team voice, team learning and team cohesion. In addition, intrinsic motivation and extrinsic motivation would have positive relationship to team innovation. This study is helpful to how to achieve team innovation and generate superior outcome.
\end{abstract}

Keywords: team communication, innovation, motivation, regression method.

\section{INTRODUCTION}

Facing complex, dynamic and competitive business environment, one person is hardly satisfying all aspects of the project needed, so teamwork become a trend of model of dealing with this challenge in organizations [14]. Then teamwork has been a prerequisite for a successful event [7]. In addition, some experts find that innovation is considered as a crucial factor for organizational survival and success where innovation is a general mean about novel ideas, procedures, or processes within a team rather than specific mean of invention [14]. To make a team become more innovative, leadership of team which is most important factor should be investigated, because an effective leadership should become more a product of connections or relationships between team members to generate synergy [4] such as one plus one greater two rather than just consisting of best professionals. According to previous studies, there are some different factors of leadership researched. In this study, it focuses on what factors of leadership could facilitate team to achieve innovation based on other author's statistic study. These studies are widely from different questionary result thus it should be explicable for the subject. After this study, team could obtain some recommendation that how making team be effective and make team achieve innovation to generate superior result.

\section{RESEARCH AND HYPOTHESIS}

\subsection{The main factor of leadership ——effective communication}

An effective communication could form an environment called team voice that members could make constructive suggestions for improvement, share new ideas and discuss problem because effective communication makes member could freely express their opinion to others[14]. To achieve an effective communication, leader should make team have the psychological safety which is the shared belief that team is safe for interpersonal risk taking [13]. Only members do not afraid of penalize for different opinions or wrong opinions, the team with psychological safety is likely that members could share their ideas freely, exchange information and discuss about difficulties and do not afraid about taking risks that express different ideas from leader, which makes team form a good team voice. If not, members are afraid express opinion because they may misunderstand each otherso that there 
is nol team voice when they express different ideas. Above arguments imply:

Hypothesis 1: effective communication has positive relationship with team voice.

According to Ye's [14] study of medical devices and banking industry, it states that the correlation between effective communication and team voice is 0.48 and is statistically significant in $1 \%$ significant level. After regression analysis, the coefficient beta is 0.46 and is statistically significant in $1 \%$ significant level. So, there is likely sufficient evidence that positive relationship between communication and team voice.

Once team forms a team voice, the team voice helps to achieve innovation because team members could openly analyze, and learn from their errors, which facilitate team constantly and challenge the team members to new heights, encourage them to think freely, and to openly discuss their opinions and ideas [11]. When there has been free environment with psychological safety, team members are willing to express their new ideas more freely and more deeply so that it is likely facilitate creating more innovative ideas. Additionally, members who are in this team voice, they are more comfortable to discuss and share real thoughts [14], which looks like a beneficent cycle so that the good climate of team voice should be helpful for team innovation. On the other side, if there is no climate about freely communication, it stifles the members' innovation and creativity [10]. Thus, the hypothesis 2 came up

Hypothesis 2: team voice has positive relationship with innovation.

According to Ye's [14] study, it states that the correlation between team voice and team innovation is 0.74 and is statistically significant in $1 \%$ significant level. After regression analysis, the coefficient beta is 0.75 and is statistically significant in $1 \%$ significant level. So, there are likely sufficient evidence that positive relationship between communication and team voice.

An effective communication also facilitates forming team learning because team learning through experiment, communication, dialogue and personal mastery [5] and has psychological safety to improve team learning. The effective communication is not only help to free express, but it also gives more convert tacit knowledge within individuals to explicit knowledge shared by many team members [11]. It means that communication exchange information and knowledge among members and this atmosphere is helpful for team learning. In addition, the psychological safety satisfied requirement of team learning. Firstly, it makes all opinions are welcomed and valued [4] so everyone would like to assess new opinions, which facilitate forming the learning environment. Secondly, it is asking explicitly for contributions from team members can help enhance a learning environment. Thirdly, it makes members do not be afraid of punishing about errors and other concerns can be discussed [4]. These three elements ensure the environments for team learning. Thus, the hypothesis 3 came up:

Hypothesis 3: communication has positive relationship with team learning.

In Sarin's [11] study, the correlation between communication and team learning is 0.46 and the regression coefficient is 0.23 and is statistically significant in $0.1 \%$ significant level. In Fco's[5] study, the result shows that the coefficient gamma between team learning and effective communication is 0.54 and is statistically significant in $1 \%$ significant level. Hence there are quite sufficient evidence support that communication has positive relationship with team learning.

Effective team learning environment help team achieve innovation because innovation is viewed as a consequence of the learning process and the innovation process requires the creation and application of new knowledge [11]. It is reasonable that there are more creative ideas and more great opinion during team learning like learning new knowledge apply on a new product to makes team become innovation. Furthermore, team innovation is not only individual behavior but also collective achievement depends on whether the team has a climate that supports innovation [8]. If there is less team learning environment, there is less likely achieve team innovation. What is more, when changes in organizational practices, strategies, and values, team learning is a necessary underpinning for innovations [5]. Especially facing the change in short time and members facing the stress under these high pressure, effective team learning is more important because it is likely to be a particularly important means of enabling team members to effectively counter and cope with these negative effects and psychological stress [2]. It is reasonable that members who could deal with the high working pressure could generate more innovative ideas than team without effective team learning environment. Hence, these arguments imply:

Hypothesis 4: team learning has positive relationship with innovation.

In Sarin's [11] study, the correlation between team learning and innovation is 0.34 and after regression analysis, the regression coefficient is 0.35 and is statistically significant in $0.1 \%$ significant level. In Fco's [5] study, the result shows that the coefficient beta between team innovation and team learning is 0.21 and is statistically significant in $0.1 \%$ significant level. Hence there is quite sufficient evidence support that team learning has positive relationship with innovation.

An effective communication improves forming team 
cohesion because leader who has effective communication could integrate the opposing interests of the different members, forming a unit that enables to maximum intelligence of the team [5]. Communication creates a two-way situation among team members so that open communication, mutual respect, and trust are helpful to maintain close social relationships and group cohesion [1]. For example, if there are some disagreements existing in team, one team with effective communication could solve it by discussion but the other without it might generate a gap between members with opposite opinions, which is negative influence of team cohesion and injures generating effective outcomes. So, the hypothesis 5 came up:

Hypothesis 5: effective communication has positive relationship with team cohesion

In Fco's [5] study, it is stated that the coefficient gamma between team cohesion and effective communication is 0.21 and is statistically significant in $0.1 \%$ significant level. It is thought as sufficient for positive relationship between effective communication and team cohesion.

Team cohesion could facilitate team innovation because team members with cohesion have complementary skills and interactions so that team could ease obtaining planned objectives and the innovation [5]. Team members who are forming as a unit rather than individuals could gather all power and knowledge focusing on one target because team total output will be a function of the team's potential minus coordination costs [13]. If team does not have cohesion and separate his power so that there is too much coordination cost and cannot achieve the superior outcome. Moreover, team cohesion also has more opportunities for cross-functional knowledge fertilization, preventing localized and isolated problem solving [11]. When team could cross different field knowledge and solve each problem by whole team's power, it is more likely to generate more innovative and successful result. Above statements assume:

Hypothesis 6: team cohesion has positive relationship with team innovation

In Fco's [5] study, the result shows that the coefficient beta between team innovation and team cohesion is 0.16 and is statistically significant in $1 \%$ significant level. So, it is sufficient evidence prove that team cohesion has positive relationship with team innovation.

\subsection{The main factor of leadership ——satisfy members' need}

Leaders should try satisfy all members needs because they can increase motivation of team members by showing concern about the interests, expectations, and feelings of team members and by being available and accessible to team members' needs for achievement of innovation [2]. The different motivations like intrinsic motivation, extrinsic motivation could motivate members achieve innovation through different aspect.

Intrinsic motivation could improve team achieving innovation because when leaders succeed in increasing employee commitment, and the overall team motivation, an organization will become more innovative in the long-term [7]. Intrinsic motivation consists of activity which the individual performs for the pleasure or satisfaction [12] and it is crucial importance in task complement especially in innovation because employees want to make a meaningful impact rather than just desiring a paycheck [4]. Once leader satisfies members' need like happiness, members are willing to make effort in because their engagement is driven by the enjoyment and they derive from the activity itself [9]. It means that member with intrinsic motivation would volunteer paying effort in team and keep this in long term. Then team innovation relies on the satisfaction and well-being of its members [6], so members with intrinsic motivation are more likely to generate innovative ideas. Thus, above arguments imply:

Hypothesis 7: intrinsic motivation has positive relationship with team innovation

In Oguz' [9] study, the regression coefficient between innovation and intrinsic motivation is 0.133 and is statistically significant at $5 \%$ significant level. In Tamara's [12] study, the correlation between innovation and intrinsic motivation is 0.123 but is statistical insignificant at any level. In regression analysis, the coefficient beta is -0.096 and is also insignificant. In this case, it may be because external factors such as an intense workload could act as such constraints team innovative ideas despite a high intrinsic motivation for these tasks [12]. Moreover, due to insignificance, the coefficient is weak and there is not rejecting the hypothesis. Overall, it is likely to prove that intrinsic motivation has positive relationship with team innovation.

Extrinsic motivation could facilitate team innovation because it motivates people's behavior like working harder. Extrinsic motivation is stimulated from the outside offering economic incentives, promotions or recognition, among other rewards [12]. So, reward system would be an effective method to make members positive attitude on work because the more its profit allocation, the more the total return of the effort, which induces the more efforts [3]. It is reasonable for individuals who would pay more effort when they could gain more return. Then more effort paying in team, the more possible generate novel ideas. However, profit allocation should be comparable with effort because 
some people may become "free riders" if the level of their individual effort is not a significant component of their remuneration [4]. When one person makes much more effort than the other one but he just receives little more remuneration than the other, he would not be willing to pay more effort in next time due to paying is not comparable with gaining so that there is negative influence on innovation. Supposing:

Hypothesis 8: extrinsic motivation has positive relationship with team innovation

In Oguz's [9] study, the regression coefficient between innovation and intrinsic motivation is 0.115 and is statistically significant at $1 \%$ significant level. In Tamara's [12] study, the correlation between innovation and intrinsic motivation is 0.119 but is statistical insignificant at any level. In regression analysis, the coefficient beta is 0.128 but is also insignificant at any level. Hence, there are evidence prove that extrinsic motivation has positive relationship with team innovation.

\section{CONCLUSION}

This thesis analyses some factor impacts on team innovation basing on second hand statistical data. Firstly, team with effective communication including psychological safety could promote to forming team voice environment then this domestic climate facilitates members generate more innovative ideas. In addition, members could facilitate to forming team learning environment through effective communication. Once there is team learning, members with this climate could support innovation. Thirdly, team with effective communication is helpful to form team cohesion and team with cohesion could gather all members' power to generate novel ideas. Moreover, team satisfies members need could stimulate members' intrinsic motivation and extrinsic motivation. Intrinsic motivation motivates members to be willing to engage in teamwork and team is more likely to engender innovation. As for extrinsic motivation makes members pay more effort in teamwork under reward system and it also motivates generate novel ideas. According to empirical study, data almost proves above arguments. Therefore, these factors could be some recommendation for team and team leader in work process so that they can achieve more innovative and generate superior outcome. However, in this thesis, it does not consider external factor of team like high performance pressure influences on team innovation. Furthermore, in future, there would be teamwork between groups and groups. All in all, team innovation is a crucial factor to sustain organization in long term and become more competitive in industries and should further study in more perspective.

\section{REFERENCES}

[1] Burke, C.S., Stagl, K.C., Klein, C., Goodwin, G.F., Salas, E. and Halpin, S.M. (2006). What type of leadership behaviors are functional in teams? A meta-analysis., The Leadership Quarterly 17(3), 288-307.

[2] Carmeli, A., Reiter-Palmon, R., \& Ziv, E. (2010). Inclusive leadership and employee involvement in creative tasks in the workplace: The mediating role of psychological safety. Creativity Research Journal, 22, 250-260.

[3] Changfeng Wang, Yuwen Cen, Rui Sun, Hongbin Ying, Optimal distribution of profit and leadership for a sustainable collaborative $R \& D$ projects, Journal of Cleaner Production, Volume 313, 2021, 127874, ISSN 0959-6526,

[4] Day, D.V., Gronn, P. and Salas, E. (2004). Leadership capacity in teams. The Leadership Quarterly, 15(6), 857-880.

[5] Fco.Javier Lloréns Montes, Antonia Ruiz Moreno, Victor García Morales,Influence of support leadership and teamwork cohesion on organizational learning, innovation and performance: an empirical examination, Technovation, Volume 25, Issue 10, 2005, Pages 1159-1172, ISSN 0166-4972

[6] McShane, S., Olekalns, M., Newman, A., and Travaglione, T. (2019). Organisational Behaviour 6e; Emerging Knowledge. Global Insights. McGraw-Hill Education Australia.

[7] Michela Giudici, Viachaslau Filimonau, Exploring the linkages between managerial leadership, communication and teamwork in successful event delivery, Tourism Management Perspectives, Volume 32, 2019, 100558, ISSN 2211-9736

[8] Mumford, M. D., Scott, G. M., Gaddis, B., \& Strange, J. M. (2002). Leading creative people: Orchestrating expertise and relationships. The Leadership Quarterly, 13, 705-750.

[9] Oguz A. Acar, Motivations and solution appropriateness in crowdsourcing challenges for innovation, Research Policy, Volume 48, Issue 8, 2019, 103716, ISSN 0048-7333

[10] Pearce, C. L. (2004). The future of leadership: Combining vertical and shared leadership to transform knowledge work. Academy of Management Executive, 18(1), 47-57.

[11] Sarin, S. and McDermott, C. (2003). The effect of team leader characteristics on learning, knowledge application, and performance of cross-functional 
new product development teams. Decision Sciences, 34(4), 707-739.

[12] Tamara González-González, Desiderio J. García-Almeida, Frontline employee-driven innovation through suggestions in hospitality firms: The role of the employee's creativity, knowledge, and motivation, International Journal of Hospitality Management, Volume 94, 2021, 102877, ISSN 0278-4319

[13] Thomas A. O'Neill, Eduardo Salas, Creating high performance teamwork in organizations, Human Resource Management Review, Volume 28, Issue 4, 2018, Pages 325-331, ISSN 1053-4822

[14]Ye, Q., Wang, D., and Guo, W. (2019). Inclusive leadership and team innovation: The role of team voice and performance pressure. European Management Journal, 37(4), 468-480. 